\title{
Micro-Tomography to Study High-performance Sandwich Structures
}

\author{
Peter Davies $^{1,{ }^{*}}$, Dominique Choqueuse ${ }^{1}$, Gael Bourbouze ${ }^{2}$ \\ ${ }^{1}$ Materials \& Structures group, IFREMER, 29280 Plouzané, France \\ ${ }^{2}$ CRT Morlaix, 29600, France \\ * Corresponding author : P. Davies, Tel 003329822 4777, Fax 003329822 4535, email address :
Peter.Davies@ifremer.fr
}

\begin{abstract}
:
Although X-radiography has been widely used in studies of damage in composite materials, microtomography has received less attention, due to the high cost and limited availability of equipment. However, micro-tomographic analysis is a powerful tool, allowing 3D images of sections through sandwich materials to be obtained without specimen preparation. Four examples from a recent study are presented here, which show how micro-tomography can provide unique information on the quality of honeycomb sandwich structures, information on damage mechanisms and internal details of through thickness reinforcement in pinned foam cores.
\end{abstract}

Keywords: Inspection, Adhesive, Meniscus, Pins, Damage 


\section{INTRODUCTION}

Traditionally X-radiography has played an essential role in understanding how damage develops in fibre reinforced composites [1,2]. Transverse cracks and delaminations can be revealed, though dye penetrants may be needed to enhance contrast. Micro-focus radiography has also proved useful in studying when delaminations start to propagate in test specimens [3], and helped to define the initiation criterion in the current mode I delamination test standard [4]. In recent years various tomographic methods have also been applied to study materials. These are all based on scanning a sample from different directions and reconstructing the three dimensional geometry based on its absorption coefficient variations. Detailed descriptions of the analysis can be found elsewhere $[5,6]$. Micro-computed X-ray tomography ( $\mu \mathrm{CT}$ ) was developed for medical imaging in the early 1970's [7] and is a particularly powerful tool to investigate the internal structure of materials. An X-ray source illuminates the samples, the attenuations of transmitted rays are recorded, the sample or the source is then rotated and a new image is obtained. This is repeated over at least $180^{\circ}$ and the 3-D image is built up from the images. According to the equipment and test conditions the resolution in commercial systems is around tens of microns, but smaller samples allow higher resolution to be achieved.

A recent review summarized a number of early applications, most of which were performed using medical scanners [8]. Some of these date from the 1980's but more widespread use has been limited by the high cost of equipment and the limited number available. This is now changing, and several recent publications have shown the advantages of this technique for composite studies. For example, Schell et al revealed fibre bundles and porosity in GFRP plates produced by RTM [9], while various authors have used $\mu \mathrm{CT}$ to determine the spatial characterization of reinforcements in 3-D fabric composites [10-12]. Moffat et al applied $\mu \mathrm{CT}$ to study damage micro-mechanisms in carbon fibre reinforced composites [13], using the European Synchrotron Radiation Facility. The high resolution achieved $\left(1.4 \mu \mathrm{m}^{3}\right.$ voxel size $)$ enabled local displacements to be quantified. This 
equipment was also used to study damage introduced under compression loading of glass filled epoxy syntactic foams [14]. However, commercial scanners are now available which can also be very useful in damage studies, Schilling et al used a laboratory system with a spot size of $5 \mu \mathrm{m}$ to reveal micro-cracks in composites and bolted composite joint samples [15].

So far few examples of the use of $\mu \mathrm{CT}$ for studies on sandwich materials have been published, though various types of foam cores have been examined [16,17]. This paper presents four examples of the use of micro-tomography to reveal the internal structure of high performance sandwich materials. The aim is to show the possibilities of this technique, using commercial tomographic equipment, to reveal important structural details which are difficult or impossible to see using traditional techniques. Its use in the control of manufacturing quality and in damage studies is described.

\section{EXPERIMENTAL EQUIPMENT}

The results shown below were obtained on a GE Phoenix V-TOM-X240 high-resolution microfocus computed tomography system Figure 1 shows the experimental set-up. The equipment is housed within a lead lined room to protect the user from radiation. For the study reported here the beam characteristics were $100 \mathrm{kV}$ and $280 \mu \mathrm{A}$ and the resolution was $28 \mu \mathrm{m}^{3}$ voxcel. 

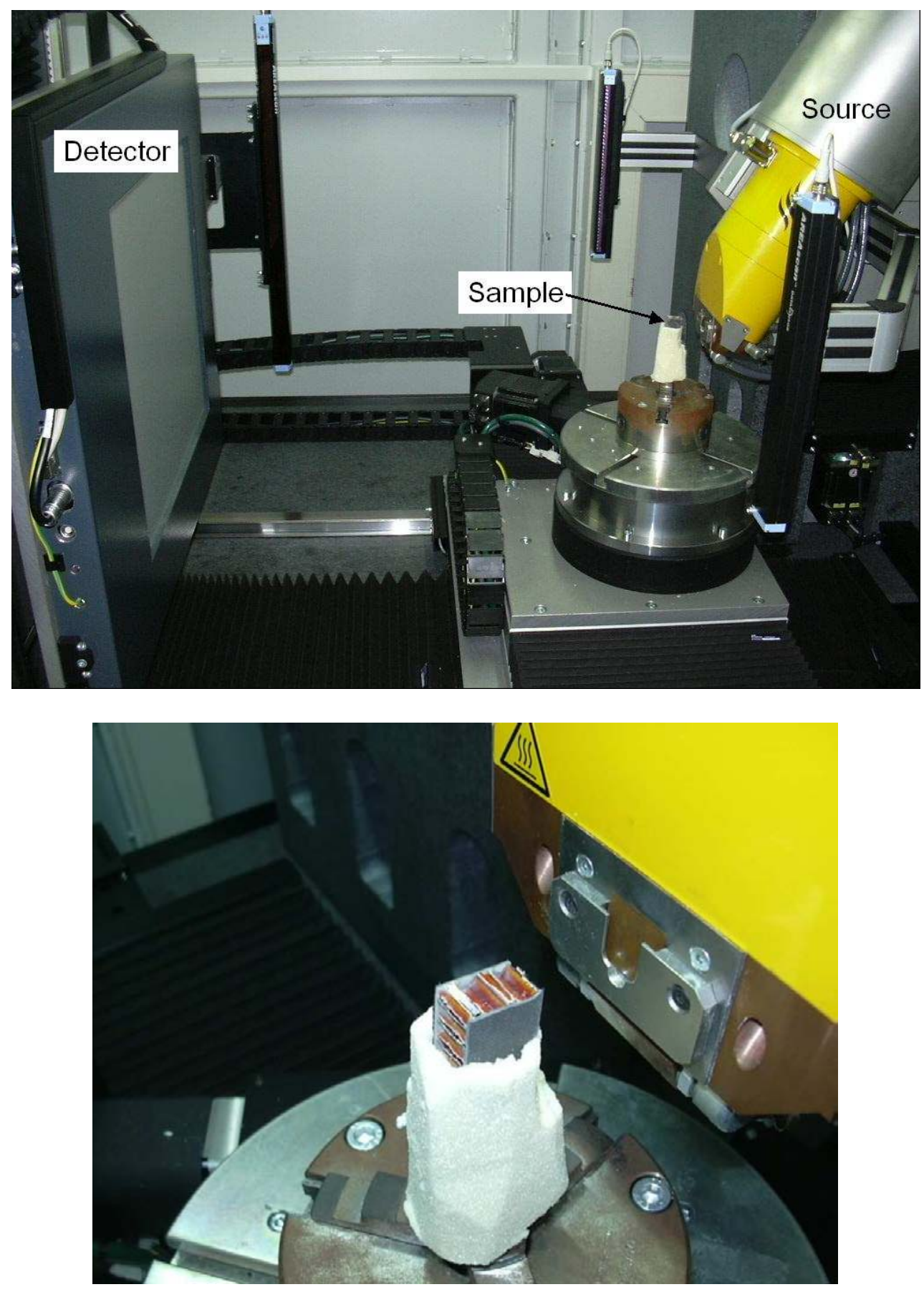

Figure 1. a) Experimental set-up, b) Sample position (20x20 $\left.\mathrm{mm}^{2}\right)$

The sample is held in a lightweight foam as shown in Figure $1 \mathrm{~b}$ and rotated through $360^{\circ}$. Up to 1000 images can be recorded in each of the $\mathrm{x}, \mathrm{y}$ and $\mathrm{z}$ directions. The number of images is then only limited by storage space, a sample typically produces 1 GByte of data. The resolution depends on the size of the specimen, up to 1000 pixels correspond to each dimension, so for a $20 \mathrm{~mm}$ edge cube one pixel corresponds to 20 microns. These images are assembled to produce a 3-D image, using 
software developed for medical scanners. The resulting images can then be visualized and analyzed.

\section{RESULTS}

Four examples will be presented, using materials from a recent study of sandwich structures for racing yachts [18]. The first two involve honeycomb sandwich structures composed of $\pm 45^{\circ}$ carbon/epoxy skins on a $48 \mathrm{~kg} / \mathrm{m}^{3}$ Nomex core. The second two involve a foam core with the same facings but through thickness composite pins, for a similar overall core density. Table 1 shows the material details. In all cases the sandwich samples were $13 \mathrm{~mm}$ thick, surface dimensions were either $(40 \mathrm{x} 40) \mathrm{mm}^{2}$ or $(20 \times 20) \mathrm{mm}^{2}$.

\begin{tabular}{|l|l|l|}
\hline Reference & Core & Fabrication \\
\hline Nomex ${ }^{\circledR}$ & $\begin{array}{l}64 \mathrm{~kg} / \mathrm{m}^{3}, \\
12 \mathrm{~mm} \text { thick }\end{array}$ & Oven $100^{\circ} \mathrm{C}$ \\
\hline Pinned foam & $\begin{array}{l}\text { Rohacell } 31 \mathrm{~kg} / \mathrm{m}^{3}+\text { pins at } 30^{\circ} \\
12 \mathrm{~mm} \text { thick }\end{array}$ & Autoclave $1 \mathrm{~atm} 120^{\circ} \mathrm{C}$ \\
\hline
\end{tabular}

Table 1. Material details

i) Honeycomb core quality control

Honeycomb cores are widely used in both aerospace and marine applications. Their performance is strongly dependent on the quality of the skin/core interface which is governed by the behaviour of a film adhesive during cure. Several studies have focussed on this area [19-20] and it is clear that the meniscus which forms when the adhesive flows into the honeycomb alveoles is one of the parameters affecting skin/core fracture energy. However, the meniscus dimensions can vary significantly as manufacturing conditions change. In order to examine the influence of this parameter either sections are cut through the sample or fracture surfaces are examined. 
A second parameter is the presence of defects within the adhesive layer. These are very difficult to visualize and quantify without extensive electron microscopy, and little work has been published concerning this type of defect.

In order to examine these two parameters different honeycomb samples have been examined, first using optical microscopy then by micro-tomography.

Figure 2 shows a traditional view of the edge of a $40 \times 40 \mathrm{~mm}^{2}$ sample after cutting. This image provides little information on either of the two parameters mentioned above.

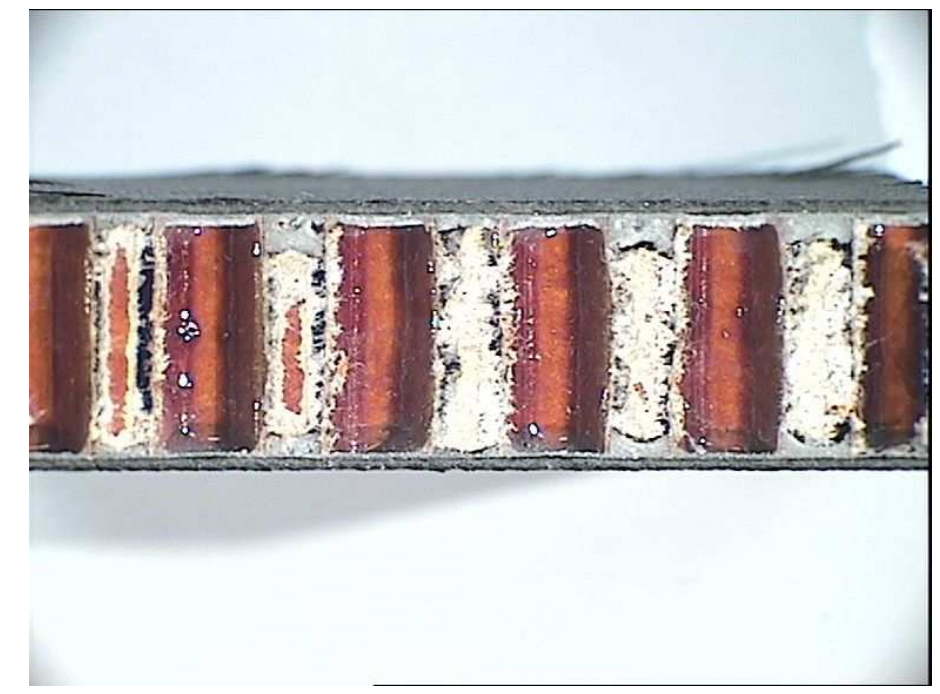

Figure 2. Honeycomb sandwich sample edge, optical microscope.

The sample shown in Figure 2, with no additional preparation, was then analysed by microtomography. Figure 3 shows an example of the type of images produced at each point at a similar scale to that shown in Figure 2 except that this is a section through the centre of the sample. The core structure is now clearer, it is apparent that the sandwich is not symmetrical, (as can also be noted in Figure 2), the upper adhesive layer is thicker than the lower and it appears to contain defects which are easier to see in Figure 3 than Figure 2. 


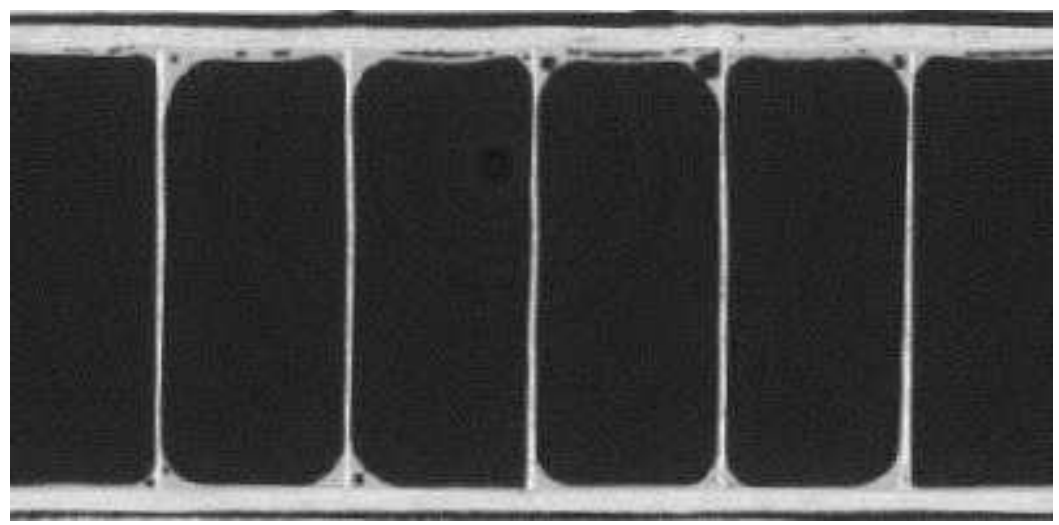

Figure 3. Tomographic image for one plane in the sample shown in Figure 2.

Using the image analysis software the user can then step through the sample, in steps of 0.04 $\mathrm{mm}$ here. For example, examining the plane parallel to the skins it is possible to study regions from within one skin (to check the fibre orientations for example), through the adhesive layer examining each individual meniscus in three dimensions, e.g. Figure 4, which details some of the porosity in the adhesive, through the honeycomb core, Figure 5, to check core geometry, and through to the second skin. All this information is stored after a tomographic scan which takes about ten minutes on the equipment employed here.

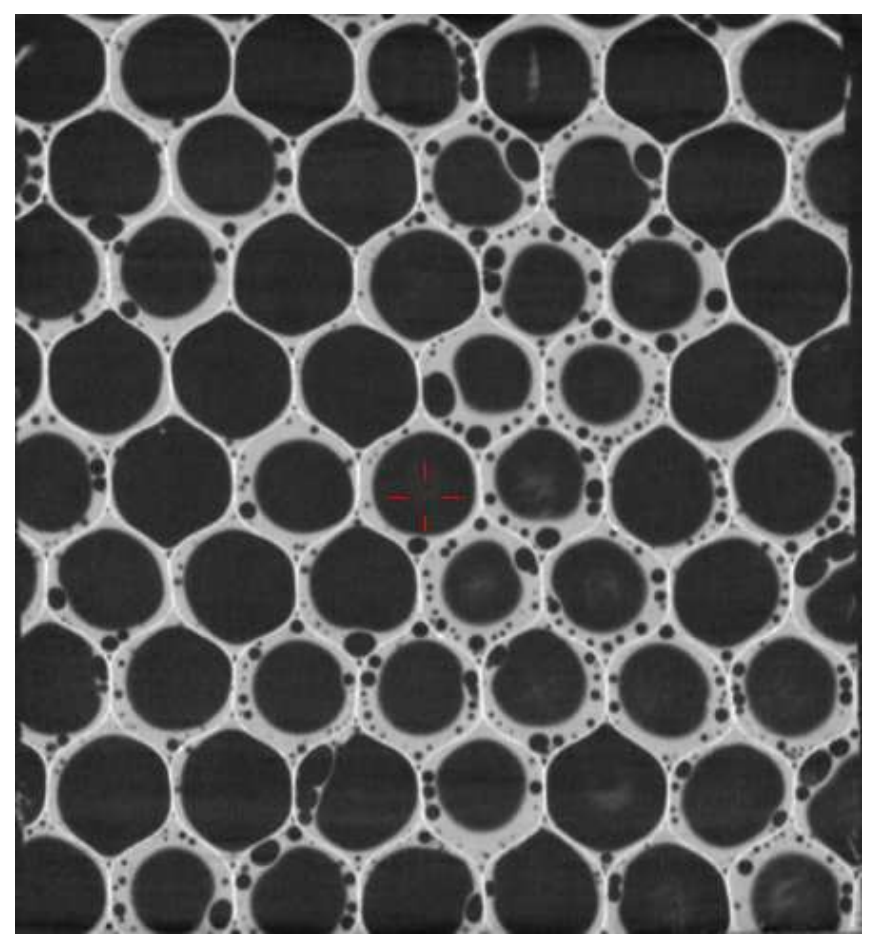

Figure 4. Section through meniscus, showing air bubbles near upper skin in Figure 3. 


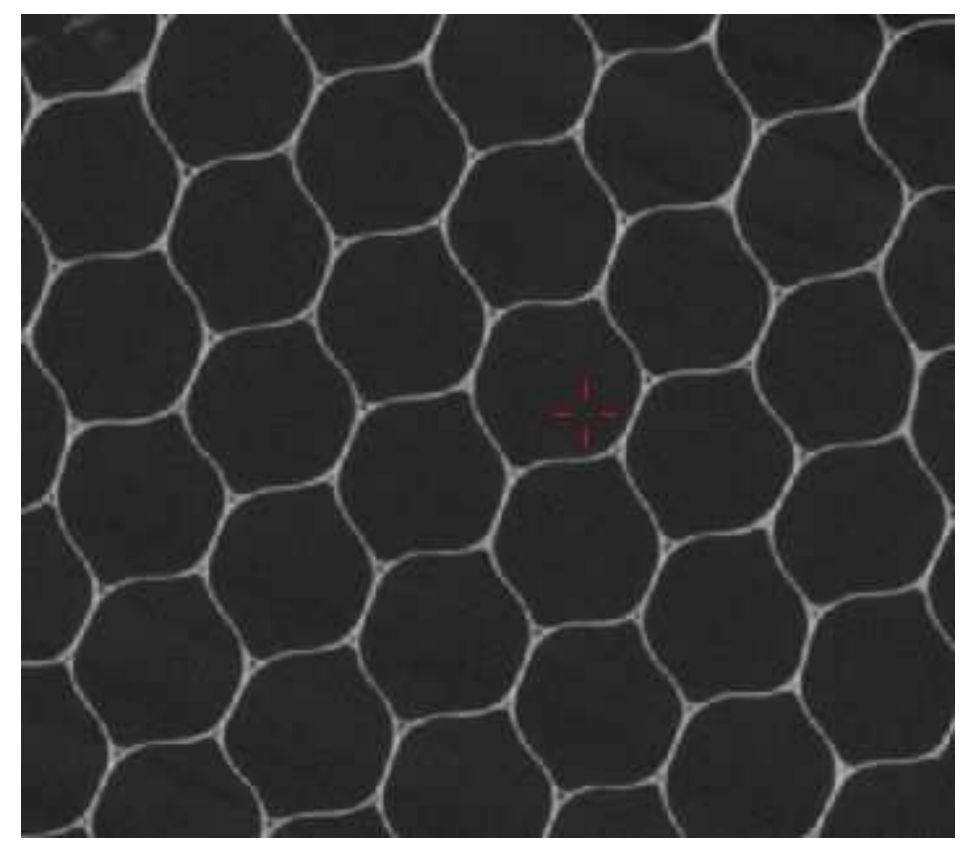

Figure 5. Section through centre of specimen. Nominal core cell size (between flats) is $5 \mathrm{~mm}$.

Figure 4 shows that there is good wetting between the core and the adhesive but there are also a large number of voids in the adhesive. As a quality control tool, on witness samples cured with sandwich structures for example, this technique provides a very large amount of information, and could prove very valuable in improving manufacturing conditions.

ii) Compression damage detection in honeycomb core

A second example concerns detection of damage. One of the most frequent causes of failure in honeycomb structures is local crushing. Standard tests have been developed to measure compression behaviour [21] but few studies have related test results to damage mechanisms. This is of particular importance when micro-mechanics models are proposed, the subject of several recent studies [22,23].

A series of $20 \times 20 \mathrm{~mm}^{2}$ samples was prepared, by interrupting crush tests at different applied strain levels, from the end of the non-linear region on the load-displacement plot to beyond the load drop. Figure 6 shows the different conditions. Tests on samples 1 and 2 were stopped at points 
corresponding to a small and larger non-linear load-displacement response. The test on sample 3 was stopped as soon as the first load drop was noted, the final sample number 4 was subjected to only a slightly higher compression displacement but the unstable load drop makes it hard to interrupt the test at an intermediate load.

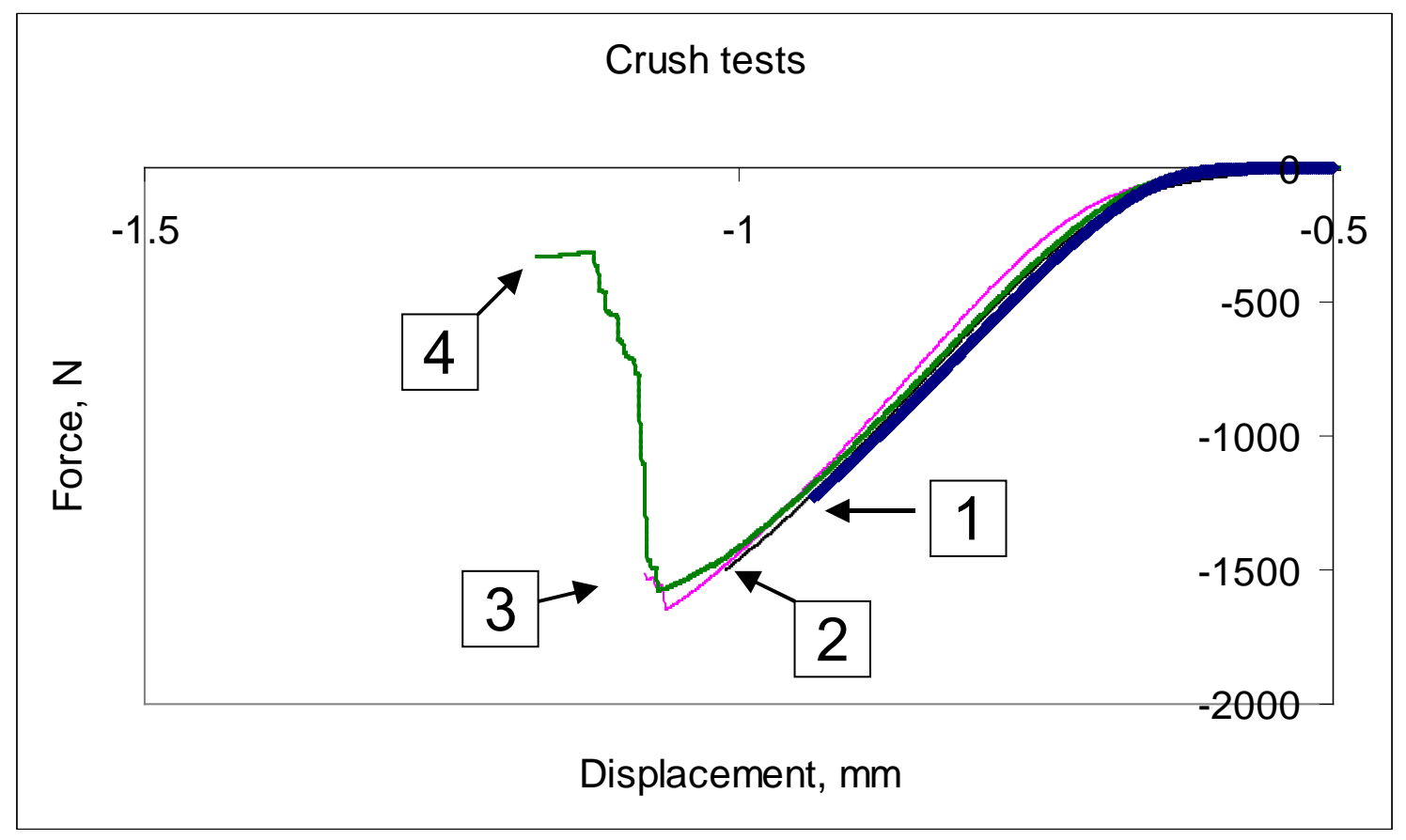

Figure 6. Flatwise compression test load-displacement plots from 4 tests, interrupted after different degrees of crushing.

The edges of these samples were then examined visually, before being scanned in the micro-tomograph to detect internal damage. Figure 7 shows an example of the optical microscope images for samples 2, 3 and 4 . 

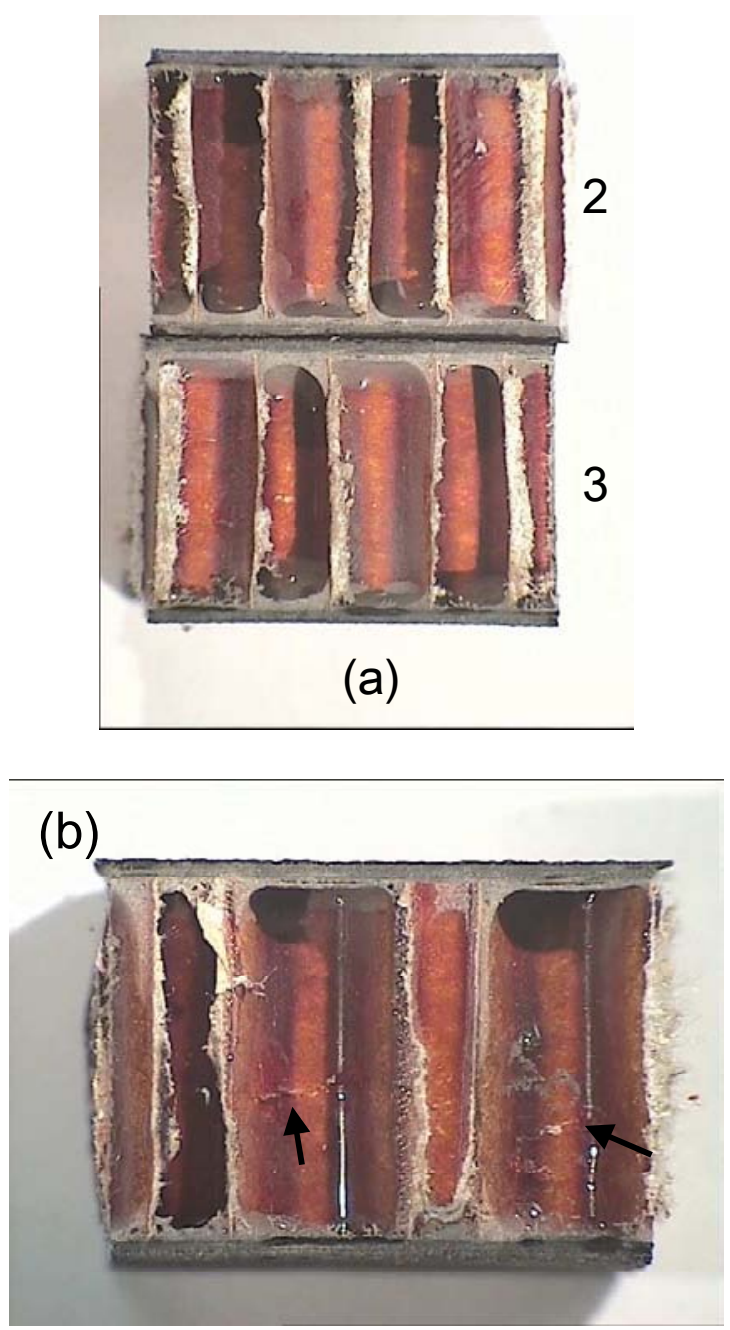

Figure 7. Optical microscopy, a) Samples 2 and 3, b) Sample 4.

Arrows indicate fine cracks in cell walls in sample 4.

No damage was noted during optical examination of samples 1 to 3. Damage can be observed in the cell walls of sample 4 however, as thin white lines showing that the resin has creased and cracked, but it requires close examination to detect these. It should also be noted that this is damage at a free, unsupported edge of the sample which may not be representative of what happens at the interior of the sample. These samples were then examined by tomography Figure 8 shows a section through the centre of samples 2 and 3, these were both scanned at the same time one above the other. 


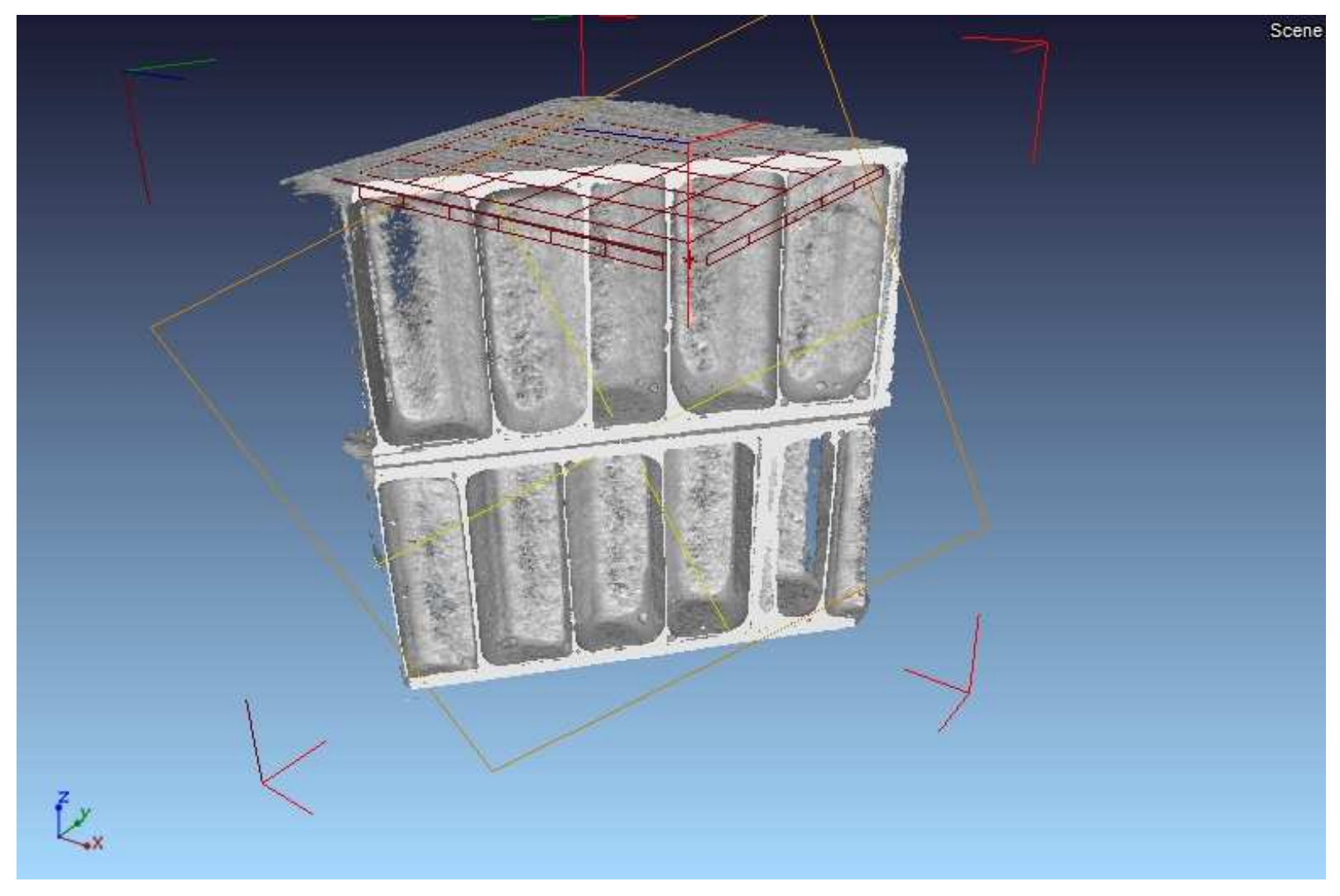

Figure 8. Reconstructed tomographic diagonal section through samples 2 (upper) and 3.

The cell walls are intact and there is no sign of permanent buckling in either sample, indicating that the non-linear behaviour on the load-displacement plot is due to elastic or visco-elastic buckling mechanisms rather than plastic damage, even at the point just after the load drop

Figure 9 shows an example of tomographic images for sample 4. A section through the centre of the core and two perpendicular sections at the same point are shown. Here, extensive permanent cell wall damage is apparent. The position of the damage is in the central free region of the core height, it does not appear to be related to the meniscus for this sample. Both $20 \times 20$ and $40 \times 40 \mathrm{~mm}^{2}$ samples showed similar behaviour, the smaller sample is presented here as they allow higher resolution to be obtained. 

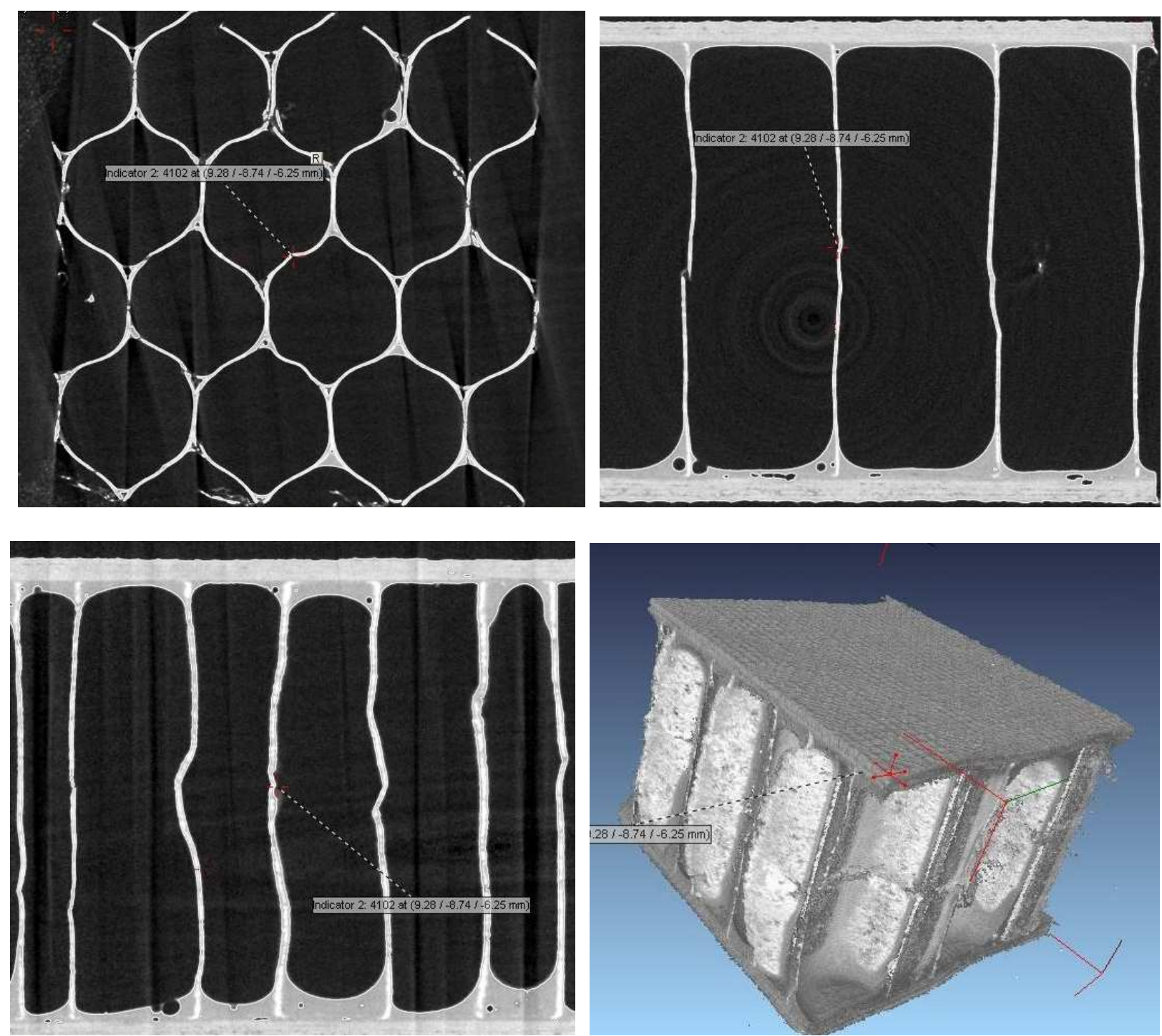

Figure 9. Three views of buckled cell walls, sample 4, markers show the same central point on the four views.

The rapid investigation of the internal structure of honeycomb sandwich materials, without having to section and risk introducing further damage, is very attractive and offers considerable possibilities for damage studies, particularly to detect and quantify internal impact damage.

iii) Pinned foam core quality control

Another example of the possibilities of $\mu \mathrm{CT}$ concerns pinned foam core sandwich materials. In order to improve the out-of-plane performance of foam cores 'z-pins', composed of pultruded unidirectionally reinforced carbon fibres, can be inserted [24,25]. These form a complex three 
dimensional structure, Figure 10a, and once the sandwich has been cured their position is quite difficult to check; the foam core makes it difficult to locate the pins in a section, Figure 10b, and sectioning tends to result in pins being deformed and pulled out of position. Cartié used conventional X-radiography to identify deformed shapes of through-thickness titanium alloy pins in sandwich panels [24]. Figure 10c shows a tomographic section through the sample shown in Figure $10 \mathrm{~b}$.

a.

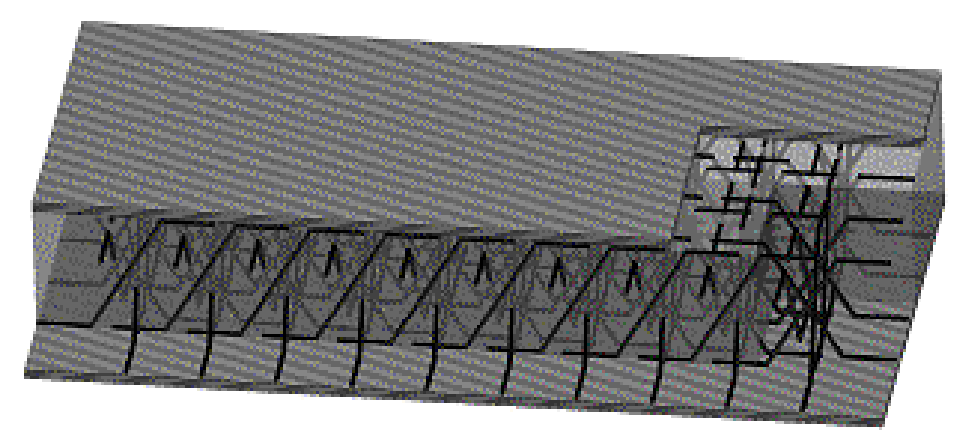

b.

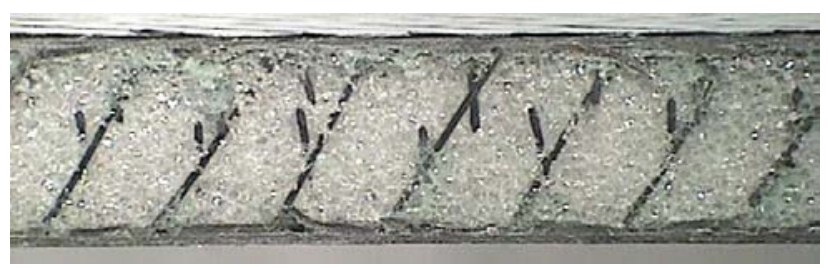

c.

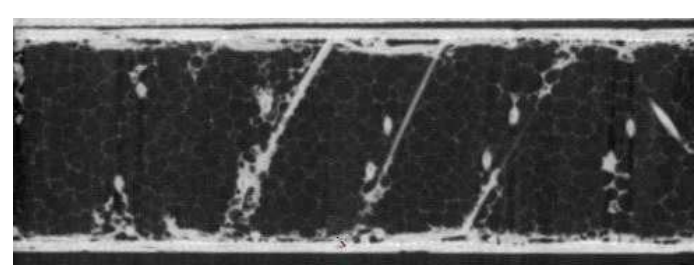

Figure 10. Pinned foam core sandwich.

a) Schematic representation, b) Section through sandwich, optical microscope

c) Tomographic image for one plane in the sample shown in Figure 10b.

First it is interesting to note that the structure of the foam core can be detected. These are much lighter at $31 \mathrm{~kg} / \mathrm{m}^{3}$ than the cores studied in [16], which were $130 \mathrm{~kg} / \mathrm{m}^{3} \mathrm{PVC}$ foams, and this suggests that $\mu \mathrm{CT}$ may be useful for foam cell damage studies, to examine cell size and density variations for example. The pinned network is not clearly shown here, as the image shows only one 
slice and it is necessary to step through the volume to reconstruct their 3-dimensional nature. However, the tomographic images do enable the pin/adhesive interface to be examined in detail, by stepping through the sandwich thickness from the skin and stopping in this plane as shown in Figure 11. This region is virtually impossible to visualize by other techniques, but it is here that the pins are anchored to the sandwich skins and knowledge of this region is important in optimising mechanical performance.

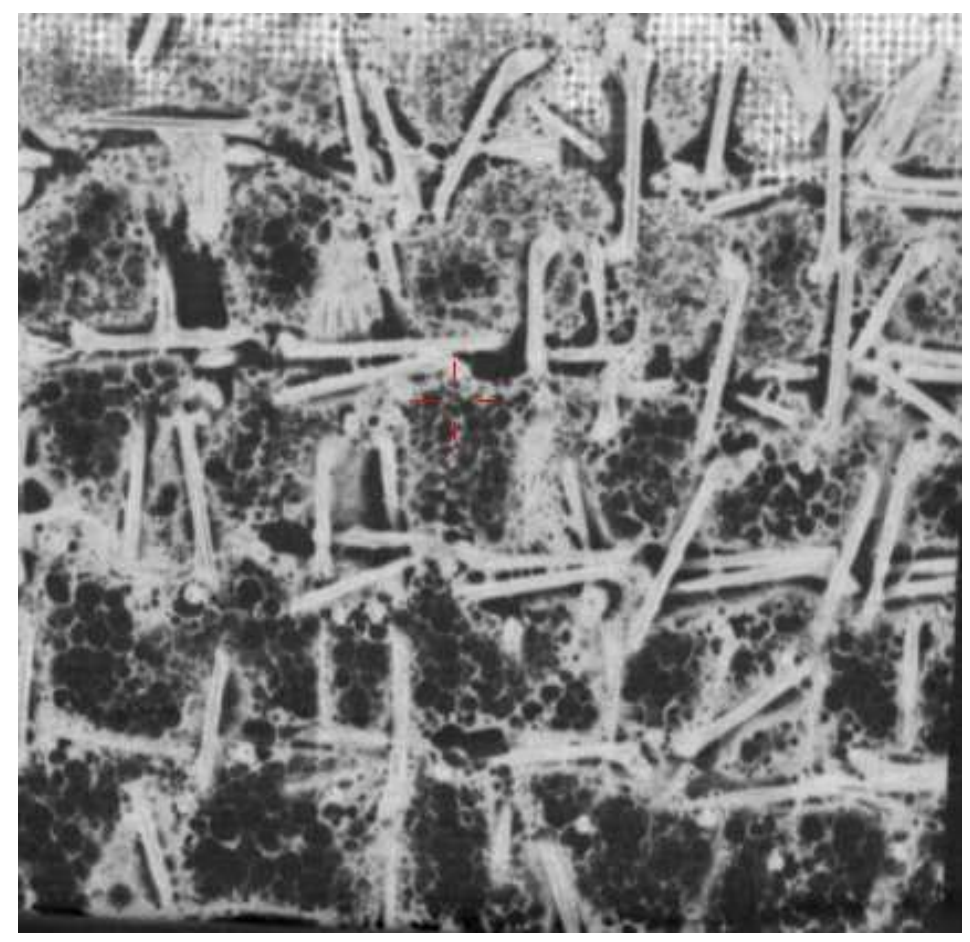

Figure 11. Adhesive layer showing folded pins at the core/skin interface plane.

iv) Compression damage detection in pinned foam core

A sample which had been subjected to a crush test up to the first load drop was then examined both optically, and by tomography. Figure 12 shows the optical image. The pins are not broken, but certain have debonded from the skin. 


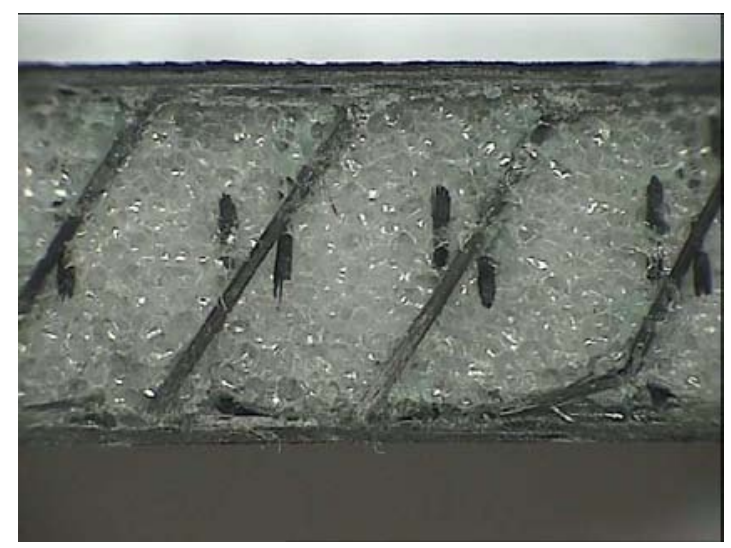

Figure 12. Section through core after crush test, optical microscope

The same sample was then examined in the micro-tomograph. Figure 13 shows an example of the images obtained in the three planes. At the mid-plane perpendicular to the facings the groups of four white points indicate the pin positions. The two projected images, bottom left and top right, show the pins at $30^{\circ}$ to the vertical axis and several are partially debonded. Their positions and orientations can be measured The bottom right image shows the 3-D reconstruction.
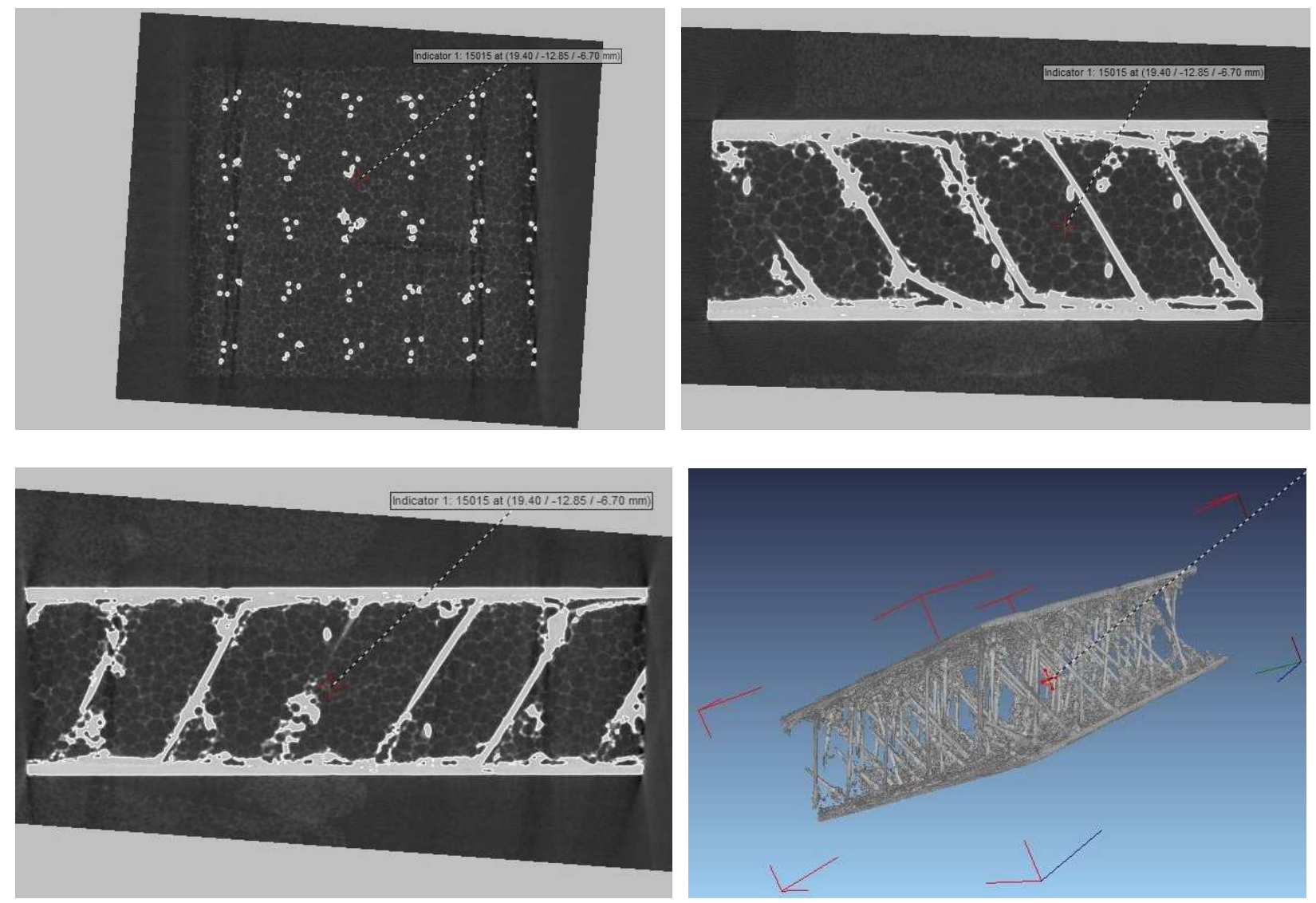

Figure 13. Examples of images of pinned foam after crush test, section through midthickness (top left) and two perpendicular sections at the same point. 


\section{CONCLUSIONS}

This paper shows four examples which illustrate how micro-tomography can be used to reveal details of the internal structure of high performance sandwich materials. Honeycomb and pinned foam core samples, with the same carbon/epoxy facings, have been examined. The results indicate that this technique offers great potential to improve manufacturing processes, by providing a quality control tool which can show defects in the adhesive layer, quantify meniscus wetting and determine the geometry of honeycomb cores. In parallel with more traditional techniques it may also prove an invaluable tool for the study of damage development, as it allows internal features to be revealed without specimen preparation, reducing the risk of introducing damage artefacts. This should result in improved understanding of the mechanical behaviour of sandwich structures.

\section{Acknowledgements}

Thanks to Ivana Partridge and Denis Cartié of Cranfield University for pinned foam core samples and Figure 10a.

\section{REFERENCES}

[1] Schulte K, Stinchcomb WW, Damage mechanisms - including edge effects - in carbon fibre reinforced composite materials, Chapter 8 in Application of Fracture Mechanics to Composite Materials, ed. Friedrich K, Elsevier 1989.

[2] Blom AF, Gradin PA, Radiography, Chapter 1 in Non-destructive testing of fibre reinforced composites Volume 1, ed Summerscales J, Elsevier 1987.

[3] de Kalbermatten T, Jäggi R, Flüeler P, Kausch HH, Davies P, Microfocus Radiography Studies During Mode I Interlaminar Fracture Toughness Tests on Composites, Journal of Materials Science Letters, 1992,11, 543-546. 
[4] ISO 15024 (2001) Fibre-reinforced plastic composites - Determination of Mode I

interlaminar fracture toughness, $\mathrm{G}_{\mathrm{IC}}$, for unidirectionally reinforced materials.

[5] Kak A, Slaney M, Principles of computerized tomographic imaging, IEEE Press, New York 1998.

[6] Bossi RH, Friddell KD, Lowrey AR, Computed Tomography, Chapter 4 in Non-destructive testing of fibre reinforced composites Volume 2, ed Summerscales J, Elsevier 1990.

[7] Hounsfield GN, Computerized transverse axial scanning tomography: Part 1, Description of system, British Journal of Radiology, 1973, 46, 1016-1022.

[8] Bayraktar E, Antolovich SD, Bathias C, New developments in non-destructive controls of the composite materials and applications in manufacturing engineering, Journal of Materials Processing Technology, Volume 206, Issues 1-3, 12 September 2008, Pages 30-44

[9] Schell JSU, Reggli M, van Lenthe GH, Muller R, Ermani P, Micro computed tomography determination of glass fibre reinforced polymer meso-structure, Comp Sci \& Tech 66, 2006, 201622.

[10] Pandita SD, Verpoest I, Prediction of the tensile stiffness of weft knitted fabric composites based on X-ray tomography images, Composites Science and Technology, Volume 63, Issue 2, February 2003, Pages 311-325

[11] Desplentere F, Lomov SV, Woerdeman DL, Verpoest I, Wevers M, Micro-CT characterization of variability in 3D textile architecture, Comp. Sci \& Tech., 2005,

Volume 65, Issue 13, October 2005, Pages 1920-1930

[12] Kosek M, Vodolan J, Study of textile composite structure using CT and optical microscopy, Proc ICCM15, Durban, 2005.

[13] Moffat AJ, Wright P, Buffière J-Y, Sinclair I, Spearing SM, Micromechanisms of damage in $0^{\circ}$ splits in a [90/0]s composite material using synchrotron radiation computed tomography, Scripta Materiala 59, 2008, 1043-46.

[14] Adrien J, Maire E, Gimenez N, Sauvant-Moynot V, Experimental study of syntactic foams by 
in-situ X-ray tomography, Acta Materiala, 55, 2007, 1667-79.

[15] Schilling PL, Karedla BR, Tatiparthi AK, Verges MA, Herrington PD, X-ray computed microtomography of internal damage in fiber reinforced polymer matrix composites, Comp. Sci \& Tech, 65, 2005, 2071-78.

[16] Maire E, Fazekasb A, Dendievel R, Youssef S, Cloetens P Letang JM, X-ray tomography applied to the characterization of cellular materials. Related finite element modeling problems, Comp Sci \& Tech, 63, 16, 2003, pp2431-2443

[17] Banyay GA, Shaltout MM, Tiwari H, Mehta BV, Polymer and composite foam for hydrogen storage application, Journal of Materials Processing Technology, Vol 191, 1-3, 2007, 102-105

[18] Baral N, Cartié DDR, Partridge IK, Baley C, Davies P, Improved impact performance of marine sandwich panels using through-thickness reinforcement: Experimental results, submitted to Composites Part B, 2008.

[19] Okada R, Kortschot MT, The role of the resin fillet in the delamination of honeycomb sandwich structures, Compos Sci Technol 62, 14, 2002, pp. 1811-1819

[20] Ural A, Zehnder AT, Ingraffea AR, Fracture mechanics approach to facesheet delamination in honeycomb: measurement of energy release rate of the adhesive bond, Engineering Fracture Mechanics, 70, 1, 2003, 93-103

[21] ASTM C365, Standard test method for flatwise compressive strength of sandwich core.

[22] Aminanda Y, Castanié B, Barrau J-J Thevenet P, Experimental Analysis and Modeling of the Crushing of Honeycomb Cores, Applied Composite Materials, 12, 3-4 2005, 213-227.

[23] Aktay L, Johnson AF, Kroplin B-H, Numerical modelling of honeycomb core sandwich, Engineering Fracture Mechanics, 75, 2008, 2616-2630.

[24] Cartié DDR, Fleck NA, The effect of pin reinforcement upon the through-thickness compressive strength of foam-cored sandwich panels, Comp. Sci \& Tech, 63 (2003), 2401-2409.

[25] Marasco AI, Cartié DDR, Partridge IK, Rezai A, Mechanical properties balance in novel Zpinned sandwich panels : Out-of-plane properties, Composites Part A, 37 (2006), 295-302. 